\title{
Allergic diseases among children: nutritional prevention and intervention
}

\author{
This article was published in the following Dove Press journal: \\ Therapeutics and Clinical Risk Management \\ 7 March 2016 \\ Number of times this article has been viewed
}

\author{
Mohamed A Hendaus ${ }^{1,2}$ \\ Fatima A Jomha ${ }^{3}$ \\ Mohammad Ehlayel ${ }^{2,4}$ \\ 'Department of Pediatrics, Section of \\ Academic General Pediatrics, Hamad \\ Medical Corporation, ${ }^{2}$ Weill Cornell \\ Medical College, Doha, Qatar; ${ }^{3}$ School \\ of Pharmacy, Lebanese International \\ University, Khiara, Lebanon; \\ ${ }^{4}$ Department of Pediatrics, Section of \\ Pediatric Allergy-Immunology, Hamad \\ Medical Corporation, Doha, Qatar
}

Correspondence: Mohamed A Hendaus Department of Pediatrics, Section of Academic General Pediatrics, Hamad Medical Corporation, PO Box 3050,

Doha, Qatar

Tel +974 44392239

Fax +9744443 957|

Emailmhendaus@yahoo.com

\begin{abstract}
Allergic diseases comprise a genetically heterogeneous group of chronic, immunomediated diseases. It has been clearly reported that the prevalence of these diseases has been on the rise for the last few decades, but at different rates, in various areas of the world. This paper discusses the epidemiology of allergic diseases among children and their negative impact on affected patients, their families, and societies. These effects include the adverse effects on quality of life and economic costs. Medical interest has shifted from tertiary or secondary prevention to primary prevention of these chronic diseases among high-risk infants in early life. Being simple, practical, and cost-effective are mandatory features for any candidate methods delivering these strategies. Dietary therapy fits this model well, as it is simple, practical, and cost-effective, and involves diverse methods. The highest priority strategy is feeding these infants breast milk. For those who are not breast-fed, there should be a strategy to maintain beneficial gut flora that positively influences intestinal immunity. We review the current use of probiotics, prebiotics, and synbiotics, and safety and adverse effects. Other dietary modalities of possible potential in achieving this primary prevention, such as a Mediterranean diet, use of milk formula with modified (hydrolyzed) proteins, and the role of micronutrients, are also explored. Breast-feeding is effective in reducing the risk of asthma, allergic rhinitis, and atopic eczema among children. In addition, breast milk constitutes a major source of support for gut microbe colonization, due to its bifidobacteria and galactooligosaccharide content. The literature lacks consensus in recommending the addition of probiotics to foods for prevention and treatment of allergic diseases, while prebiotics may prove to be effective in reducing atopy in healthy children. There is insufficient evidence to support soy formulas or amino acid formulas for prevention of allergic disease. A healthy diet, such as the Mediterranean diet, may have a protective effect on the development of asthma and atopy in children. In children with asthma and allergic diseases, vitamin D deficiency correlates strongly with asthma, allergic rhinitis, and wheezing.
\end{abstract}

Keywords: allergic, children, prebiotics, primary, probiotics, prevention, synbiotics

\section{Background}

Allergic diseases comprise a genetically heterogeneous group of chronic, immunomediated diseases ${ }^{1,2}$ that mainly involve bronchial asthma, allergic rhinitis, atopic dermatitis, food allergy, and acute urticaria. They are more prevalent among children than adults. Worldwide, respiratory allergic diseases alone, namely asthma and allergic rhinitis, affect nearly 700 million subjects. ${ }^{3}$ It has been clearly reported that the prevalence of these diseases has been on the rise for the last few decades, but at different rates, in various areas of the world. ${ }^{3,4}$ Currently, bronchial asthma is considered the most common chronic, noninfectious condition among children. ${ }^{4}$ In some industrialized countries, the prevalence of asthma is close to $35 \%-40 \%$, whereas it is less than $5 \%$ in other communities; ${ }^{5}$ furthermore, relatively new reports have shown that the prevalence of asthma is increasing in many low- and middle-income nations., ${ }^{4,6}$ cC. hereby accept the Terms. Non-commercial uses of the work are permitted without any further permission from Dove Medical Press Limited, provided the work is properly attributed. For permission for commercial use of this work, please see paragraphs 4.2 and 5 of our Terms (https://www.dovepress.com/terms.php). 
The impact of allergic diseases is tremendous on affected individuals, their families, and societies. They adversely affect quality of life and increase the rate of comorbid conditions and risk of death, as noticed in asthma. ${ }^{3,7}$ In addition, the economic burden of these diseases is considerable. This is usually related to the substantial direct medical cost (emergency department visits, physician's office visits, hospitalizations, diagnostic laboratory and radiological workup, and other modalities of therapy) and indirect medical costs (numerous absences from labor or school, reduced productivity, and diminished school performance)., ${ }^{3,7-9}$

Allergic diseases are intricate diseases resulting from the interaction of genetic and environmental factors. ${ }^{10}$ The latter include infectious agents (human rhinoviruses, respiratory syncytial virus, and mycoplasma), allergens (house dust mites, pollens, pets, and molds), pollutants, and medication exposure. ${ }^{11-13}$

During the last 2 decades, primary prevention of allergic diseases and asthma (prevention of immunological sanitization, development of IgE antibodies) has proved to be a more effective strategy than secondary prevention (preventing the development of an allergic disease following sensitization) or tertiary prevention (treatment of asthma of allergic diseases). ${ }^{14}$ As a strategy, primary prevention of allergic diseases includes 1) allergen avoidance, 2) restoration of gut microbiota-intestinal immunity relationship, 3) dietary pattern, 4) intake of modified dietary proteins in early life, and 5) micronutrients.

The Cochrane Library, Embase, Medline, and Google Scholar databases were searched in March 2015 (from inception to March 2015) for randomized controlled trials (RCTs), quasi-RCTs, and review articles that were published in English and Spanish. In addition, we searched the references of the identified articles for additional articles. We used a wide variety of different combinations of the following terms: allergy, primary, prevention, children, mothers, diet, milk, formula, breast-feeding, prebiotics, probiotics, synbiotics, Mediterranean, micronutrients, and fatty acids. We identified and reviewed 254 manuscripts, but filtered to 153 references (Figure 1). This review paper focuses on primary prevention of allergic diseases in children.

\section{Restoration of gut microbiota- intestinal immunity relationship}

Since the allergy-high-risk infant (born to one or more allergic parent, and/or allergic sibling) is healthy, the strategy of preventing immunity alteration is aimed at the preservation of the "beneficial" gut microbiota in the newborn, and

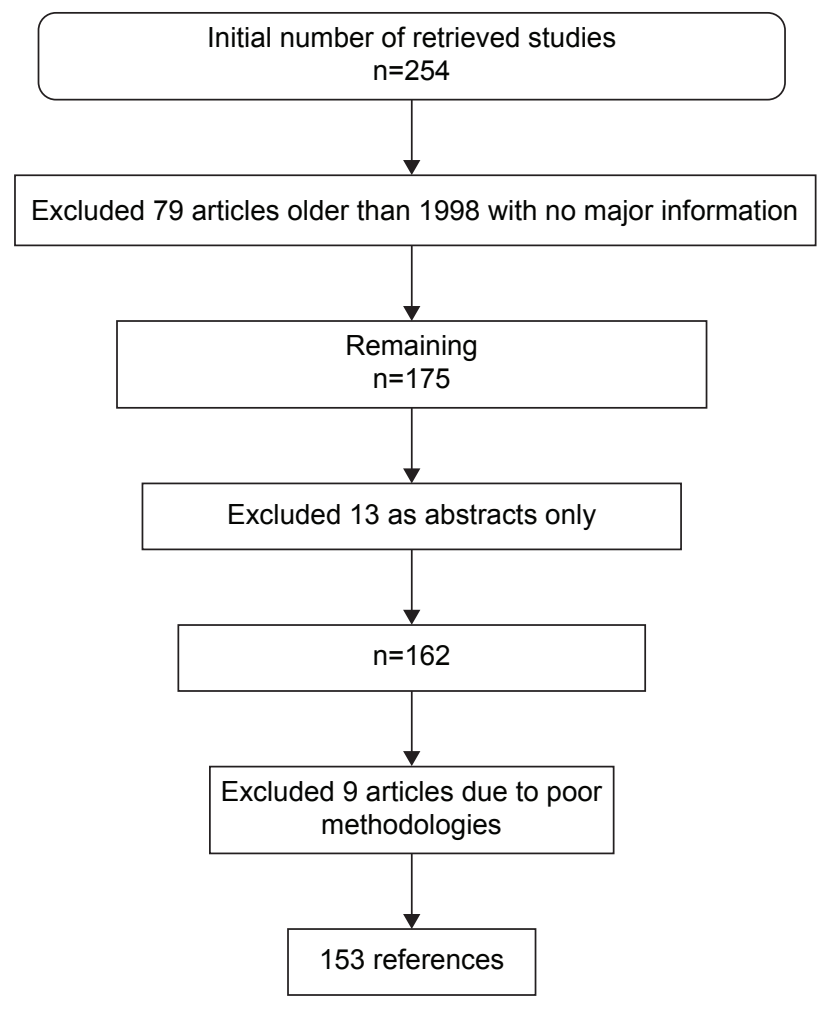

Figure I Flow diagram of selection of literature.

thus preventing deviations of the local intestinal immunity and consequently the systemic immunity to the proallergic side. To understand the rationale behind this preventive strategy, the bacterial colonization of gut, infant intestinal microbiota-intestinal immune interaction, and imbalances in the composition of the intestinal microbiota leading to allergic diseases have to be explored.

\section{Gut microbiota, intestinal immunity, and allergic diseases}

Microbial gut colonization typically commences at the time of birth, and is influenced by the load (inoculum) of the first maternal microbiota, type of delivery (cesarean section vs vaginal delivery), feeding practices (formula-feeding vs breast-feeding), and antimicrobial use. ${ }^{15-17}$ The maternal intestinal microbiota clearly determines the type of infant's intestinal microbiota in the first few months of life. ${ }^{18}$ Moreover, it takes a few months for the bacterial species to become steadily consistent, despite the early life complete colonization. ${ }^{16,19}$ At the age of 1 month, infants born via cesarean section demonstrate similar numbers of gut bacteria to those who were vaginally delivered, but with higher rates of Clostridium spp., Klebsiella spp., Enterobacteriaceae, Bacteroides spp., Bifidobacterium spp., and Escherichia coli. ${ }^{16,20,21}$ This effect extends 
beyond the age of 6 months in infants born via cesarean section, ${ }^{22}$ increasing the risk of atopy, asthma, and allergic rhinitis. ${ }^{23}$ In normal breast-fed infants, Bifidobacterium spp. predominate the gut microbiota $(60 \%-70 \%)$, compared to formula-fed infants, where Bacteroides and Clostridium spp. and Enterobacteriaceae prevail. ${ }^{16,21}$ Perturbations in the intestinal microbial profile result in the reduction of the predominance of Bifidobacterium spp. or rise of unbeneficial microbiota, leading to increased risk of allergies, infections, ${ }^{19}$ and other diseases. ${ }^{24}$

In the newborn period, the gut microbiota plays a crucial role in promoting and maintaining the mucosal immune system, both in terms of its physical factors and function, and in maintaining a very well-balanced immune response. Gut-associated mucosal lymphoid tissue becomes reactive to pathogenic bacteria but tolerant to "beneficial" bacteria. Moreover, the intestinal microbiota plays an important role in the development of tolerogenic dendritic cells from the mesenteric lymph nodes of the gutassociated mucosal lymphoid tissue and in the production of secretory $\operatorname{IgA} .^{25,26}$

The intestinal epithelia express various pathogenrecognition receptors, including Toll-like receptors and nucleotide-binding oligomerization domain-like receptors that activate immune response against pathogens. Since pathogenic bacteria and gut commensals express many of these pathogen-associated molecular patterns, there is tight control on the immune-response mechanisms so that it will recognize and specifically respond to pathogens, but at the same time remain tolerant to commensals. These mechanisms involve intestinal epithelial cells, Toll-like receptors, dendritic cells, and T-regulatory $\left(\mathrm{T}_{\text {reg }}\right)$ cells. ${ }^{27}$

It is known that T-helper (Th)-2 cells are characterized by their production of IL-4, IL-5, IL-9, and IL-13, which contribute to the development of and maintenance of allergic inflammatory process, while Th1 cells produce TNF $\alpha$ and IFN $\gamma$, which contribute in the modulation of cell-mediated immunity. ${ }^{27,28}$

$\mathrm{T}_{\text {reg }}$ cells, however, maintain immunological tolerance due to their immunomodulatory or immunosuppressive capabilities, and are key players in regulating immune response in nondisease states. ${ }^{27}$ Changes in $\mathrm{T}_{\text {reg }}$ numbers or functions are usually associated with development of allergic disease (Figure 2). Basic animal studies on germ-free mice revealed that in the absence of microbial colonization, T-cells produced more Th2 cytokines. This Th2-cell predominance was corrected with colonization of germ-free mice with Bacteroides fragilis alone, which promoted Th1 response and restored the Th1/Th2 imbalance. ${ }^{28}$ Evidence from clinical studies also demonstrated that probiotic bacteria reduced Th2 cytokine patterns while promoting Th1 response. ${ }^{29}$ The intestinal microbiota have marked immunomodulatory effects that are essential in maintaining immune tolerance. It has been proposed that certain diseases, such as eczema, asthma, allergic rhinitis, type 1 diabetes mellitus, and inflammatory bowel diseases, are linked to the dysregulation of the development of the intestinal mucosal defense system. ${ }^{30}$

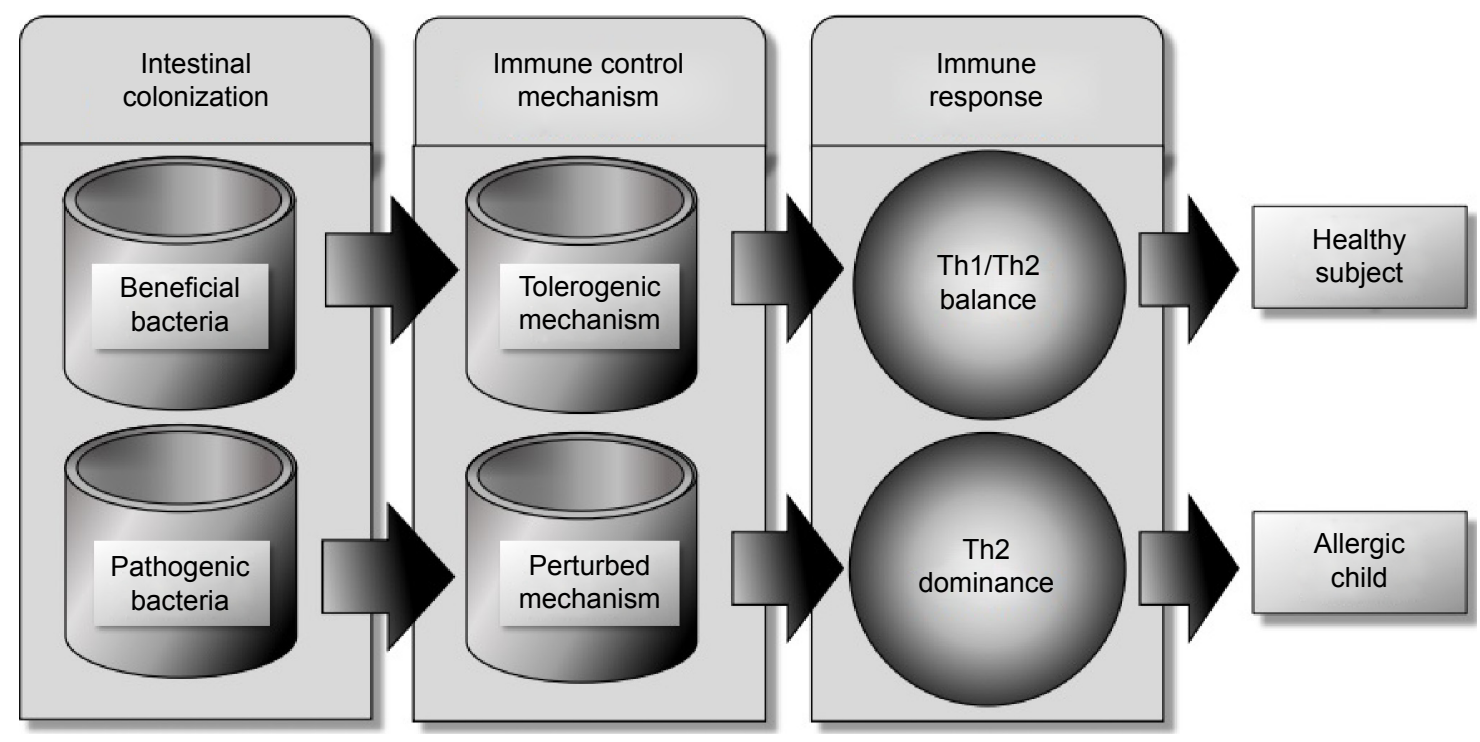

Figure 2 In early infancy, colonization with beneficial flora stimulates the intestinal immunity to develop immunotolerance through intraintestinal epithelial cells and dendritic cells and their surface markers, leading to balanced ThI/Th2 immune response.

Note: Perturbations of this process (eg, by cesarean section delivery) disrupts microbiota, deviates immune response, and induces allergic response. Abbreviation: Th, T-helper. 
The composition of intestinal microflora differs between atopic and healthy infants. ${ }^{20}$ Atopic children have lower counts of Lactobacillus, Bifidobacterium, and Bacteroides spp. ${ }^{31}$ A recent systematic review by Melli et $\mathrm{al}^{32}$ on the role of intestinal microbiota and allergic diseases among children revealed that in allergic children, early life microbiota was of lower diversity, predominantly Firmicutes; the same group of children also showed a higher amount of Bacteroidaceae and anaerobic bacteria, particularly B. fragilis, E. coli, Clostridium difficile, Bifidobacterium catenulatum, and B. bifidum, and fewer B. adolescentis, B. bifidum, and Lactobacillus. Well-conducted clinical trials have provided good data on the preventive benefit of probiotics (Lactobacillus or Bifidobacterium) in pregnant women and their infants in reducing the risk of allergic diseases, especially atopic dermatitis. . 33,34

Breast milk constitutes a major source of support to gut colonization, due to its Bifidobacterium content and its composition of a large amount of galactooligosaccharides (GOS), which selectively accelerate the growth of bifidobacteria. ${ }^{35,36}$ Multiple, recent, and large epidemiological studies confirmed the beneficial effects of breast-feeding in reducing the risk of asthma, allergic rhinitis, and atopic eczema among children. ${ }^{37-39}$

\section{Probiotics, prebiotics, and synbiotics}

Probiotics are defined as supplements that contain microorganisms (bacteria, yeast) and can change the microflora of the host. ${ }^{40,41}$ The European Food and Feed Cultures Association and the International Life Sciences Institute defined probiotic as "a live microbial food ingredient that, when consumed in adequate amounts, confers health benefits on the consumers" and "live microorganisms that, when ingested or locally applied in sufficient numbers, provide the consumer with one or more proven health benefits". ${ }^{42,43}$ Probiotics might be effective in preventing antibiotic-related diarrhea in healthy children and necrotizing enterocolitis in very low-birth-weight infants, as well as preventing childhood atopy and treating acute viral gastroenteritis; moreover, probiotics might be beneficial in the treatment of irritable bowel syndrome, chronic ulcerative colitis, infantile colic, and Helicobacter pylori gastritis. ${ }^{41}$ The strains of probiotics most commonly used are Bifidobacterium and Lactobacillus spp. ${ }^{44,45}$ which are also well known to have the capacity of resisting the physicochemical environment of the digestive tract. ${ }^{46}$

On the other hand, prebiotics are aliments or supplements that contain a variety of molecules that stimulate the activity and/or growth of the native probiotic bacteria; a common component of prebiotics is fiber/oligosaccharides..$^{41}$ In the absence of fiber in the colon, anaerobic bacteria obtain their energy from protein fermentation, producing toxic metabolites, such as phenolic and ammoniac compounds. ${ }^{47,48}$ By contrast, microbiota metabolites, such as short-chain fatty acids produce nontoxic material, such as propionate, butyrate, or acetate..$^{47,49}$ In a study conducted on rats, Gourgue-Jeannot et a $l^{50}$ found that providing a fructan (inulin, fructooligosaccharide [FOS]) diet increased the synthesis of short-chain fatty acids. Currently, the most commonly used prebiotics are soybean oligosaccharides, FOS, GOS, and inulin..$^{51,52}$ Synbiotics are simply a mix of probiotic and prebiotic, which synergistically promote the growth of beneficial bacteria. ${ }^{53,54}$

\section{Use of probiotics in prevention of allergic diseases}

\section{Asthma}

Several studies have been conducted using murine models to assess the effectiveness of probiotics in the treatment and prevention of asthma and hypersensitive airways. Blümer et $\mathrm{al}^{55}$ studied the perinatal maternal administration of probiotics in mice. The study showed that application of Lactobacillus rhamnosus GG (LGG) suppressed significantly allergic airways and peribronchial inflammation in mouse offspring. In another murine model, Feleszko et $\mathrm{al}^{56}$ found that application of either LGG or Bifidobacterium lactis (Bb12) significantly decreased pulmonary eosinophilia, airway reactivity, and antigen-specific IgE production. Moreover, the administration of a recombinant or wild-type Lactobacillus plantarum can effectively reduce airway eosinophilia following aerosolized allergen exposure. ${ }^{57}$ Furthermore coadministration of L. plantarum and Lactococcus lactis has been shown to reduce allergen-induced basophil degranulation in a murine model of birch-pollen allergy. ${ }^{58}$ Two different studies showed that oral administration of live Lactobacillus reuteri reduced hyperresponsiveness to methacholine, airway eosinophilia, and local cytokine responses. ${ }^{59,60}$ There have also been several studies conducted on human beings, including children. Stockert et $\mathrm{a}^{6}{ }^{61}$ found that using laser acupuncture and probiotics in school-age children with asthma might prevent acute respiratory exacerbations and decrease bronchial hyperreactivity. However, two studies showed no efficacy of oral L. rhamnosus administration to adolescents suffering from pollen allergy. ${ }^{62,63}$ Moreover, a systematic review of RCTs showed that the effectiveness of probiotics for the treatment of allergic rhinitis and asthma is questionable. ${ }^{64}$ 


\section{Atopic dermatitis}

Management with LGG may ameliorate eczema/dermatitis syndrome symptoms in IgE-sensitized infants, but not in non-IgE-sensitized infants. ${ }^{65}$ In IgE-sensitized children, treatment with $L$. rhamnosus results in tangible reduction in the prevalence of any IgE-associated eczema. ${ }^{65,66}$ Rosenfeldt et $a l^{67}$ reported that the use of two Lactobacillus strains (rhamnosus and reuteri) in the treatment of allergic dermatitis was effective in children with increased IgE levels. In a review that included $13 \mathrm{RCTs}$, Betsi et al ${ }^{68}$ concluded that regardless of IgE-sensitization, probiotics, especially LGG, can prevent atopic dermatitis. Vliagoftis et $\mathrm{al}^{64}$ had the same conclusion in a meta-analysis of eleven studies. Furthermore, a meta-analysis showed that administration of probiotics during pregnancy reduced the risk of atopic eczema in children aged 2-7 years whose mothers received probiotics during pregnancy (reduction 5.7\%, $P=0.022$ ) ${ }^{69}$

Regardless of the timing of administration (pregnancy or early life), probiotics seem to prevent atopic dermatitis and IgE-associated atopic dermatitis in infants..$^{70}$ Han et al ${ }^{71}$ mentioned that probiotic L. plantarum CJLP133 supplementation is of good value in the treatment of pediatric atopic dermatitis. The preventive effect of LGG on atopic eczema has been also described in infants during the first 6 months of life. ${ }^{72}$ However, Kopp and Salfeld ${ }^{73}$ presented a different opinion. In addition, Taylor et $\mathrm{a}^{74}$ challenged the use of early probiotic supplementation with L.acidophilus, and found that it did not reduce the risk of atopic dermatitis in high-risk infants, but on the contrary was linked with increased allergen sensitization in infants receiving complements. In addition, Gore et $\mathrm{a}^{75}$ found there was no usefulness from supplementation with $B$. lactis or Lactobacillus paracasei in the treatment of eczema, or benefits on the progression of allergic disease from age 1-3 years. Moreover, other authors found little evidence to support the idea of routine supplementation of probiotics to either infants or pregnant women to prevent allergic diseases in childhood. ${ }^{76,77}$

Nonetheless, two major meta-analyses and one Cochrane study inferred that probiotics were not effective for the treatment for eczema. ${ }^{78-80}$ Furthermore, RCT studies showed that the probiotic effect was not steady over the long term (4-7 years), ${ }^{72,81}$ or even in the short term (6 months). ${ }^{82}$ Dotterud et $\mathrm{a}^{83}$ conducted an RCT to assess the effect of perinatal administration of probiotics on childhood asthma or atopic sensitization. A total of 415 pregnant women were randomized to receive probiotics (LGG, L. acidophilus $\mathrm{La}-5$ and $B$. animalis subsp. lactis $\mathrm{Bb} 12$ ) or placebo. At 2 years, there were no substantial effects on asthma or atopic sensitization in the group that received probiotics compared to placebo. The heterogeneity in results in different studies is perhaps attributable to different probiotic strains used, environmental factors, such as diet or geographic region, and genetic liability. ${ }^{76,84}$

\section{Allergic rhinitis}

Probiotic treatment is beneficial in decreasing symptoms and reducing the use of relief medications in patients with seasonal and perennial allergic rhinitis. ${ }^{64,73,85,86}$ Moreover, probiotic VSL $3^{\circledR}$ (Sigma-Tau Pharmaceuticals, Inc. Gaithersburg, MD, USA) can prevent the development of Parietaria major allergen-specific local and systemic response when administered intranasally to mice. ${ }^{87}$

In a double-blind RCT, Giovannini et a ${ }^{88}$ reported that long-term (12 months) consumption of fermented milk containing L. casei may improve the health status of preschool children with allergic rhinitis. Kuitunen et al ${ }^{89}$ showed that probiotics can prevent IgE-associated allergy until the age of 5 years in cesarean-delivered children. Moreover, L. rhamnosus HN001 can protect against eczema and rhinoconjunctivitis when given in the first 2 years of life. ${ }^{90}$ Furthermore, studies have shown that fermented milk prepared with Lactobacillus gasseri-, LGG-, and B. longumsupplemented yogurt can ameliorate nasal blockage and hence be effective in seasonal allergic rhinitis, such as in Japanese cedar pollinosis. ${ }^{91-94}$

However, a meta-analysis reported no benefits of probiotic use for allergic rhinitis. ${ }^{77}$ In addition, Tamura et a ${ }^{95}$ concluded in their study that fermented milk containing L. casei strain Shirota was futile in preventing allergic symptoms, including Japanese cedar pollinosis.

\section{Food allergy}

It has been reported that oral intake of Lactobacillus or Bifidobacterium strains could improve food allergy. ${ }^{96}$ In a murine-based study, oral administration of $L$. acidophilus AD031 and B. lactis AD011 prevented ovalbumininduced food allergy in mice. ${ }^{97}$ Other studies showed that administration of $L$. casei strain Shirota or VSL3 reduced anaphylaxis in a food-allergy model in mice ${ }^{87,97,98}$ Isolauri et al ${ }^{99}$ mentioned in their study that supplementation of formulas with LGG ameliorated gastrointestinal symptoms in infants with eczema.

In contrast, administration of B. lactis $\mathrm{Bb}-12$ and $L$. case to extensively hydrolyzed formula did not improve cow's milk tolerance in infants with cow's milk allergy. ${ }^{100}$ Moreover, other studies concluded that probiotics, specifically LGG or L. acidophilus, do not protect against cow's milk 
allergy in infancy. ${ }^{74,78,96,101}$ Finally, Osborn and Sinn ${ }^{77}$ stated in their review involving 1,549 infants that the benefit of probiotics in improving food hypersensitivity is questionable.

\section{Probiotic safety in disease prevention}

Lactobacillus and Bifidobacterium as probiotics are considered to have a safe profile; however, there are limited data regarding the safety of other bacteria. ${ }^{102}$ The rate of systemic infection with probiotic strains has been reported as $0.05 \%-0.4 \%$ in a large study conducted on adults, ${ }^{103}$ but it is very rare in infants and children. ${ }^{104-106}$ Allen et a ${ }^{107}$ reported that lactobacilli and bifidobacteria are well tolerated with no adverse effects during pregnancy and in infants. Probiotic products may include hidden allergens of food, and might not be suitable for patients with allergies to cow's milk or hen's eggs. ${ }^{108}$ Other side effects of probiotics on children have been restricted to case reports. For instance, Robin et al ${ }^{109}$ reported L. rhamnosus meningitis following recurrent episodes of bacteremia in a child undergoing allogeneic hematopoietic stem cell transplantation Moreover, Vahabnezhad et $\mathrm{al}^{110}$ reported Lactobacillus bacteremia associated with probiotic use in a pediatric patient with ulcerative colitis receiving systemic corticosteroids and infliximab, while Luong et $\mathrm{al}^{111}$ reported a case of Lactobacillus empyema in an HIV-infected immunodeficient patient with a lung transplant receiving a probiotic containing LGG. Bacteremia due to Lactobacillus supplementation was also reported in an immunocompetent infant and child without gastrointestinal diseases. ${ }^{12}$ Finally, antibiotic resistance could emerge due to the long-term use of probiotics under antibiotic-selection pressure, and the resistance gene could be conveyed to other bacteria. ${ }^{113}$

\section{Use of prebiotics in prevention and treatment of allergic diseases}

It has been postulated that prebiotics in infant formulas have the potential to prevent sensitization of infants to dietary allergens. In a 2-year follow-up RCT involving 132 infants at risk of atopy because of strong parental history, Arslanoglu et $\mathrm{al}^{114}$ reported that the cumulative incidences for atopic dermatitis, recurrent wheezing, and allergic urticaria were lower in the group of infants fed with a formula with either an added mixture of FOS and GOS compared to the placebo group. Furthermore, in a prospective, double-blind, and placebo-controlled fashion, a mixture of neutral prebiotic oligosaccharides was evaluated for protective effect against allergy. A total of 92 healthy infants at risk of atopy were fed either a placebo-supplemented ( $0.8 \mathrm{~g} / 100 \mathrm{~mL}$ maltodextrin) hypoallergenic formula or prebiotic-supplemented $(0.8 \mathrm{~g} / 100 \mathrm{~mL}$ short-chain GOS/ long-chain FOS) during the first 6 months of life. The authors concluded that feeding infants with oligosaccharide prebiotics (short-chain GOS/long-chain FOS) early in life protects against atopic dermatitis and allergic rhinoconjunctivitis. ${ }^{15}$

However, in a Cochrane study, Osborn and Sinn ${ }^{116}$ found that prebiotic supplementation in infant formula does not prevent food hypersensitivity or allergic disease. In addition, prebiotics alone are inferior to synbiotics in the treatment of moderate-to-severe childhood atopic dermatitis. ${ }^{117}$

\section{Combined prebiotics and probiotics in the prevention of allergic disease}

The effect of early intervention with synbiotics, a combination of probiotics and prebiotics, on the prevalence of asthma-like symptoms in infants with high risk of allergic diseases has been investigated. In a double-blind, placebocontrolled multicenter trial, 90 infants with atopic dermatitis, age $<7$ months, were randomized to receive an infant formula with GOS/FOS and B. breve M16V mixture or formula without synbiotics; 75 children completed the 1-year follow-up, and the study showed that the prevalence of wheezing was substantially lower in the synbiotic than in the placebo group. ${ }^{118}$ However, other studies showed that synbiotic has no benefit on the cumulative occurrence of allergic diseases, but was useful in reducing IgE-associated (atopic) diseases and the occurrence of atopic eczema. ${ }^{41,119}$

\section{Modified milk formulas during early life}

Several health care practitioners recommend the use of soy-based formulas to treat infants with allergy or food intolerance. However, this is not currently recommended for prevention of allergy or food intolerance. ${ }^{120}$ However, other formulas, such as hydrolyzed formulas, have been proposed for the prevention of allergy and food intolerance in infants. ${ }^{121}$ Hydrolyzed formulas consist of cow's milk proteins that undergo enzymatic and chemical hydrolysis to decrease the peptide size, molecular weight, and allergenicity of the proteins. ${ }^{122}$ It has been postulated that when breastfeeding alone is not feasible in high-risk infants, partially hydrolyzed (casein- or whey-based) formulas are effective in preventing allergic diseases, particularly atopic dermatitis. In a systematic review, Alexander and Cabana ${ }^{123}$ reviewed 18 articles to study the role of partially hydrolyzed $100 \%$ whey (pHF-W) protein infant formula in reducing the risk of atopic dermatitis. The study showed that feeding with pHF-W statistically significantly decreased the risk of atopic manifestations (summary relative-risk estimate $0.56,95 \%$ 
confidence interval [CI]: 0.40-0.77). The authors concluded that exclusive breast-feeding should be the first choice of infant nutrition in the first 6 months of life. However, for infants who are not exclusively breast-fed, feeding with pHF-W instead of cow's milk formula reduces the risk of atopic dermatitis in those with a family history of allergy. Moreover, Szajewska and Horvath ${ }^{124}$ conducted a metaanalysis to study the evidence of a pHF-W formula in the prevention of allergic diseases. The authors concluded that for all allergic diseases and atopic eczema/atopic dermatitis, the use of the $\mathrm{pHF}$ compared with standard formula decreased the risk of allergy in high-risk children. However, in a Cochrane systematic review, Osborn and Sinn ${ }^{121}$ concluded that compared to exclusive breast-feeding, alimenting with hydrolyzed formula in the early days of infancy resulted in no significant difference in childhood cow's milk allergy or infant allergy. With regard to extensively hydrolyzed (caseinor whey-based) formulas, the literature indicates that they are effective for primary prevention of allergy in high-risk infants, but they are not cost-effective when compared with partially hydrolyzed formulas. ${ }^{125}$

\section{Dietary patterns (Mediterranean diet)}

Changes in dietary customs play an important role in the prevalence of symptoms of allergic diseases. ${ }^{126-132}$ The Western diet constitutes a high intake of processed and red meat, fast food, sugary drinks, and full-fat dairy products, with minimal vegetables. This diet pattern contains high levels of polyunsaturated fatty acids (PUFAs) and $\omega 6$ fatty acids, which are risk factors for some chronic and allergic diseases. ${ }^{133,134}$ Meanwhile, the Mediterranean diet comprises increased use of unrefined grain, fruits, and vegetables, moderate utilization of dairy products and milk, and low meat intake. ${ }^{135}$ Several studies have mentioned the protective role the Mediterranean diet plays in some chronic diseases and allergies, ${ }^{133,135-138}$ perhaps due to its antioxidant and immunoregulatory properties. ${ }^{139}$

For instance, de Batlle et al ${ }^{137}$ conducted a cross-sectional study that included 1,476 Mexican children (6-7 years old). Nutritional data of the children's intake in the previous 12 months and their mothers' intake during pregnancy were gathered. The study showed that maintaining a Mediterranean diet was inversely associated with wheezing ever (odds ratio [OR] $=0.64$, 95\% CI: 0.47-0.87), asthma ever (OR $=0.60$, 95\% CI: 0.40-0.91), rhinitis ever (OR $=0.41,95 \% \mathrm{CI}$ : $0.22-0.77$ ), sneezing ever ( $\mathrm{OR}=0.79,95 \% \mathrm{CI}: 0.59-1.07)$, and itchy/watery eyes $(\mathrm{OR}=0.63,95 \% \mathrm{CI}: 0.42-0.95)$. Chatzi and Kogevinas ${ }^{133}$ echoed those results, and concluded that maintaining a Mediterranean diet in the early years can have a protective effect on the development of asthma and atopy in children. For older children, Arvaniti et al ${ }^{136}$ included in his study 700 children 10-12 years old from 18 schools located in Athens, Greece. The authors concluded that adherence to a Mediterranean diet was inversely linked to the likelihood of asthma symptoms. Moreover, in a study conducted on adults showed that adherence to the Mediterranean diet reduced the risk of uncontrolled asthma by $78 \%(\mathrm{OR}=0.22$, 95\% CI: $0.05-0.85 ; P=0.028) .{ }^{139}$

In a meta-analysis and systematic review, Garcia-Marcos et $\mathrm{al}^{140}$ studied the influence of the Mediterranean diet on asthma in children. The outcomes measured were prevalence of "current wheeze", "current severe wheeze", or "asthma ever". The authors used ORs to compare the highest tertile of the scores with the lowest. In addition, random-effect meta-analyses for the whole group of studies were used and stratified by Mediterranean setting (centers $<100 \mathrm{~km}$ from the Mediterranean coast). The study concluded that following a Mediterranean diet is associated with lower prevalence of "asthma ever" (OR $=0.86$, 95\% CI: $0.78-0.95, P=0.004$ [all]; OR $=0.86,95 \%$ CI: 0.74 $1.01, P=0.06$ [Mediterranean]; $\mathrm{OR}=0.86,95 \%$ CI: $0.75-0.98$, $P=0.027$ [non-Mediterranean]), "current wheeze" $(\mathrm{OR}=0.85$, 95\% CI: $0.75-0.98 ; P=0.02)$, driven by Mediterranean centers $(\mathrm{OR}=0.79,95 \% \mathrm{CI}: 0.66-0.94 ; P=0.009)$, and "current severe wheeze" (OR $=0.82,95 \% \mathrm{CI}$ : $0.55-1.22, P=0.330$ [all]; $\mathrm{OR}=0.66,95 \% \mathrm{CI}: 0.48-0.90, P=0.008$ [Mediterranean]; and $\mathrm{OR}=0.99$, 95\% CI: $0.79-1.25, P=0.95$ [non-Mediterranean]; with the difference between regions being significant). However, Tamay et $\mathrm{al}^{141}$ concluded in their large study that the protective effect of the Mediterranean diet on allergic rhinitis in elementary school children was not significant.

\section{Micronutrients}

As Hippocrates famously noted, "Let food be thy medicine". Perhaps the factors with the greatest effect on modulating atopic expression are nutritional in nature. For those at risk, exposure to certain foods may contribute to severe, lifelong asthma or food allergies. Other foods, rich in antiinflammatory antioxidants, may in fact ameliorate allergic responses to environmental stimuli. It is unlikely to be one factor that is solely responsible for unlocking genomic tendencies toward atopy. ${ }^{142}$

An association between seasonal allergies and food allergies has been reported. In some individuals, allergic rhinitis due to specific pollens is connected to oral allergy symptoms due to certain fruits and vegetables. ${ }^{143}$ Interestingly, organic versions of these same foods may be tolerated by patients who experience reactions with conventional 
produce. It may be that the pesticide stimulation of the immune system is responsible for this difference, or it may be that the level of antioxidant nutrients in organic foods is more concentrated. ${ }^{144}$ There is no clear evidence on the role of vitamins $\mathrm{A}$ or $\mathrm{C}$ in primary prevention of allergic diseases. However, vitamin D in particular is of increasing interest in atopic prevention and treatment. A growing number of studies have consistently demonstrated that a majority of children are vitamin D-insufficient or -deficient. In children with asthma and allergic diseases, vitamin D deficiency is a strong correlate for asthma, allergic rhinitis, and wheezing. ${ }^{145}$ Furthermore, research indicates that vitamin D deficiency functions as a strong predictor of asthma in children. ${ }^{146-148}$

In a Cochrane study conducted by Bath-Hextall et al, ${ }^{149}$ the authors assessed the following micronutrients once thought to be protective against eczema: sunflower oil (linoleic acid) versus fish oil versus placebo, docosahexaenoic acid versus control, oral zinc sulfate compared to placebo, vitamin D versus placebo, vitamin D versus vitamin E versus vitamins D plus E together versus placebo, pyridoxine versus placebo, sea buckthorn seed oil versus sea buckthorn pulp oil versus placebo, selenium versus selenium plus vitamin $\mathrm{E}$ versus placebo, and hempseed oil versus placebo. The study concluded that there was no conclusive evidence of the benefit of dietary supplements in eczema.

\section{Essential fatty acids}

More recent studies have looked at the role of essential fatty acids in reducing allergic disease. The evidence is very good for prenatal prevention of atopy when mothers ingest higher amounts of $\omega 3$ PUFAs. ${ }^{150}$ It also appears that newborns who ingest breast milk relatively rich in $\omega 3$ are less likely to develop allergic symptoms. ${ }^{151,152}$ This effect is most prominent in those babies at highest risk genetically for allergic diseases. Interestingly, the results of directly feeding infants PUFAs are not as clear. Studies of dietary modification with $\omega 3$ PUFAs in children at high risk demonstrated reduction in atopy. ${ }^{153,154}$ Perhaps it is the balance of the two that is most important, and one must also take into account preexisting dietary deficiencies and genomic factors. More research is clearly needed in this realm before universal recommendations can be made.

\section{Conclusion and recommendations}

Multiple, recent, and large epidemiological studies have confirmed the beneficial effects of breast-feeding in reducing the risk of asthma, allergic rhinitis, and atopic eczema among children. Breast milk constitutes a major source of support to gut colonization, due to its bifidobacteria content and by providing a large amount of GOS, which selectively accelerate the growth of bifidobacteria. The literature lacks consensus in recommending the addition of probiotics to foods for prevention and treatment of allergic diseases. Moreover, probiotics must not be provided to immunocompromised children. Despite many studies portraying safety and efficacy in the use of probiotics during pregnancy and lactation, more evidence is required before a strong recommendation can be made. Probiotics in infant formula are safe. However, more RCTs are needed to compare human milk versus infant formula supplemented with probiotics.

Prebiotics may prove to be effective in reducing atopy in healthy children. Prebiotics in infant formula have been found to be safe, but clinical efficacy has to be investigated more, not to mention the high cost burden on families. There is insufficient evidence to support soy formulas or amino acid formulas for prevention of allergic disease. Partially hydrolyzed formulas are of use in infants at high risk of atopic dermatitis in the first 6 months of life instead of intact cow's milk protein formula. A healthy diet, such as the Mediterranean diet, may have a protective effect on the development of asthma and atopy in children. In children with asthma and allergic diseases, vitamin D deficiency is a strong correlate for asthma, allergic rhinitis, and wheezing. It is worth mentioning that the current deficiency of evidence of efficacy does not mean that future clinical investigations will not establish tangible health benefits for probiotics, prebiotics, diet, and vitamin supplementation.

\section{Acknowledgments}

The authors would like to thank Hamad Medical Corporation for the support and ethical approval (HMC Research Protocol No. 15455/15).

\section{Disclosure}

The authors report no conflicts of interest in this work.

\section{References}

1. Westly E. Genetics: seeking a gene genie. Nature. 2011;479(7374): S10-S11.

2. Shurin MR, Smolkin YS. Immune-mediated diseases: where do we stand? Adv Exp Med Biol. 2007;601:3-12.

3. Masoli M, Fabian D, Holt S, Beasley R. The global burden of asthma. Available from: http://www.ginasthma.org/local/uploads/files/ GINABurdenReport_1.pdf. Accessed July 17, 2015.

4. International Study of Asthma and Allergies in Childhood. The Global Asthma Report 2011. Paris: International Union Against Tuberculosis and Lung Disease; 2011. Available from: http://isaac.auckland.ac.nz/ resources/Global_Asthma_Report_2011.pdf. Accessed: January 11, 2016.

5. Soriano JB, Campos HS. Epidemiology of asthma. 2012. Available from: http://www.sopterj.com.br/profissionais/_revista/2012/n_02/03. pdf. Accessed: January 11, 2016

6. Hong S, Son DK, Lim WR, et al. The prevalence of atopic dermatitis, asthma, and allergic rhinitis and the comorbidity of allergic diseases in children. Environ Health Toxicol. 2012;27:e2012006. 
7. Meltzer EO, Bukstein DA. The economic impact of allergic rhinitis and current guidelines for treatment. Ann Allergy Asthma Immunol. 2011; 106(2 Suppl):S12-S16.

8. Civelek E, Sahiner UM, Yüksel H, et al. Prevalence, burden, and risk factors of atopic eczema in schoolchildren aged 10-11 years: a national multicenter study. J Investig Allergol Clin Immunol. 2011;21(4):270-277.

9. American Lung Association. Trends in asthma morbidity and mortality. 2012. Available from: http://www.lung.org/finding-cures/our-research/ trend-reports/asthma-trend-report.pdf. Accessed July 17, 2015.

10. Holloway JW, Yang IA, Holgate ST. Genetics of allergic disease. J Allergy Clin Immunol. 2010;125(2 Suppl 2):S81-S94.

11. Guilbert TW, Denlinger LC. Role of infection in the development and exacerbation of asthma. Expert Rev Respir Med. 2010;4(1):71-83.

12. Asher MI, Stewart AW, Mallol J, et al. Which population level environmental factors are associated with asthma, rhinoconjunctivitis and eczema? Review of the ecological analyses of ISAAC Phase One. Respir Res. 2010;11:8.

13. Nishimura KK, Galanter JM, Roth LA, et al. Early life air pollution and asthma risk in minority children: the GALA II \& SAGE II studies. Am J Respir Crit Care Med. 2013;188(3):309-318.

14. World Health Organization. Prevention of allergy and allergic asthma. 2003. Available from: http://whqlibdoc.who.int/hq/2003/WHO_NMH_ MNC_CRA_03.2.pdf?ua=1. Accessed July 17, 2015.

15. Rigon G, Vallone C, Lucantoni V, Signore F. Maternal factors pre- and during delivery contribute to gut microbiota shaping in newborns. Front Cell Infect Microbiol. 2012;2:93.

16. Azad MB, Konya T, Maughan H, et al. Gut microbiota of healthy Canadian infants: profiles by mode of delivery and infant diet at 4 months. CMAJ. 2013;185(5):385-394

17. Wall R, Ross RP, Ryan CA, et al. Role of gut microbiota in early infant development. Clin Med Pediatr. 2009;3:45-54.

18. Grönlund MM, Grześkowiak L, Isolauri E, Salminen S. Influence of mother's intestinal microbiota on gut colonization in the infant. Gut Microbes. 2011;2(4):227-233.

19. Morelli L. Postnatal development of intestinal microflora as influenced by infant nutrition. J Nutr. 2008;138(9):S1791-S1795.

20. Hong PY, Lee BW, Aw M, et al. Comparative analysis of fecal microbiota in infants with and without eczema. PLoS One. 2010;5(4): e9964.

21. Avershina E, Storrø O, Øien T, et al. Bifidobacterial succession and correlation networks in a large unselected cohort of mothers and their children. Appl Environ Microbiol. 2013;79(2):497-507.

22. Grönlund MM, Lehtonen OP, Eerola E, Kero P. Fecal microflora in healthy infants born by different methods of delivery: permanent changes in intestinal flora after cesarean delivery. J Pediatr Gastroenterol Nutr. 1999;28(1):19-25.

23. Kolokotroni O, Middleton N, Gavatha M, Lamnisos D, Priftis KN, Yiallouros PK. Asthma and atopy in children born by caesarean section effect modification by family history of allergies - a population based cross-sectional study. BMC Pediatr. 2012;12:179.

24. Aziz Q, Doré J, Emmanuel A, Guarner F, Quigley EM. Gut microbiota and gastrointestinal health: current concepts and future directions. Neurogastroenterol Motil. 2013;25(1):4-15.

25. Kau AL, Ahern PP, Griffin NW, Goodman AL, Gordon JI. Human nutrition, the gut microbiome and the immune system. Nature. 2011; 474(7351):327-336.

26. Groer MW, Luciano AA, Dishaw LJ, Ashmeade TL, Miller E, Gilbert JA. Development of the preterm infant gut microbiome: a research priority. Microbiome. 2014;2:38.

27. Di Mauro A, Neu J, Riezzo G, et al. Gastrointestinal function development and microbiota. Ital J Pediatr. 2013;39:15.

28. Mazmanian SK, Liu CH, Tzianabos AO, Kasper DL. An immunomodulatory molecule of symbiotic bacteria directs maturation of the host immune system. Cell. 2005;122(1):107-118.

29. Ghadimi D, Fölster-Holst R, de Vrese M, Winkler P, Heller KJ, Schrezenmeir J. Effects of probiotic bacteria and their genomic DNA on $\mathrm{T}_{\mathrm{H}} 1 / \mathrm{T}_{\mathrm{H}} 2$-cytokine production by peripheral blood mononuclear cells (PBMCs) of healthy and allergic subjects. Immunobiology. 2008;213(8):677-692.
30. Matsuzaki T, Takagi A, Ikemura H, Matsuguchi T, Yokokura T. Intestinal microflora: probiotics and autoimmunity. J Nutr. 2007;137(3 Suppl 2): 798S-802S.

31. Penders J, Thijs C, van den Brandt PA, et al. Gut microbiota composition and development of atopic manifestations in infancy: the KOALA birth cohort study. Gut. 2007;56(5):661-667.

32. Melli LC, do Carmo-Rodrigues MS, Araújo-Filho HB, Solé D, de Morais MB. Intestinal microbiota and allergic diseases: a systematic review. Allergol Immunopathol (Madr). Epub 2015 May 15.

33. Kim JY, Kwon JH, Ahn SH, et al. Effect of probiotic mix (Bifidobacterium bifidum, Bifidobacterium lactis, Lactobacillus acidophilus) in the primary prevention of eczema: a double-blind, randomized, placebo-controlled trial. Pediatr Allergy Immunol. 2010;21(2 Pt 2): e386-e393.

34. Rautava S, Kainonen E, Salminen S, Isolauri E. Maternal probiotic supplementation during pregnancy and breast-feeding reduces the risk of eczema in the infant. J Allergy Clin Immunol. 2012;130(6):1355-1360.

35. Garrido D, Dallas DC, Mills DA. Consumption of human milk glycoconjugates by infant-associated bifidobacteria: mechanisms and implications. Microbiology. 2013;159(Pt 4):649-664.

36. Mikami K, Kimura M, Takahashi H. Influence of maternal bifidobacteria on the development of gut bifidobacteria in infants. Pharmaceuticals (Basel). 2012;5(6):629-642.

37. Ehlayel MS, Bener A. Duration of breast-feeding and the risk of childhood allergic diseases in a developing country. Allergy Asthma Proc. 2008; 29(4):386-391.

38. Simons E, Dell SD, Beyene J, To T, Shah PS. Is breastfeeding protective against the development of asthma or wheezing in children? A systematic review and meta-analysis. Allergy Asthma Clin Immunol. 2011;7 Suppl 2:A11.

39. Al-Makoshi A, Al-Frayh A, Turner S, Devereux G. Breastfeeding practice and its association with respiratory symptoms and atopic disease in 1-3-year-old children in the city of Riyadh, central Saudi Arabia. Breastfeed Med. 2013;8(1):127-133.

40. Salminen S, Bouley C, Boutron-Ruault MC, et al. Functional food science and gastrointestinal physiology and function. Br J Nutr. 1998; 80 Suppl 1:S147-S171.

41. Thomas DW, Greer FR. Probiotics and prebiotics in pediatrics. Pediatrics. 2010;126(6):1217-1231.

42. European Food and Feed Cultures Association. Food culture: definition of food cultures (FC). 2015. Available from: http://www.effca.org/ content/food-culture. Accessed January 11, 2015.

43. Ashwell M. Concepts of Functional Foods. Brussels: International Life Sciences Institute; 2002. Available from: http://www.ilsi. org/Publications/01_Ashwell_ILSIFuncFoods2002.pdf. Accessed January 11, 2015.

44. Fooks LJ, Gibson GR. Probiotics as modulators of the gut flora. Br J Nutr. 2002;88 Suppl 1:S39-S49.

45. Heyman M, Menard S. Probiotic microorganisms: how they affect intestinal pathophysiology. Cell Mol Life Sci. 2002;59(7):1151-1165.

46. Isolauri E, Salminen S, Ouwehand AC. Microbial-gut interactions in health and disease. Probiotics. Best Pract Res Clin Gastroenterol. 2004; 18(2):299-313.

47. Manning TS, Gibson GR. Microbial-gut interactions in health and disease. Prebiotics. Best Pract Res Clin Gastroenterol. 2004;18(2): 287-298.

48. Kolida S, Tuohy K, Gibson GR. Prebiotic effects of inulin and oligofructose. Br J Nutr. 2002;87 Suppl 2:S193-S197.

49. Kim CH, Park J, Kim M. Gut microbiota-derived short-chain fatty acids, T cells, and inflammation. Immune Netw. 2014;14(6): 277-88.

50. Gourgue-Jeannot C, Kalmokoff ML, Kheradpir E, et al. Dietary fructooligosaccharides alter the cultivable faecal population of rats but do not stimulate the growth of intestinal bifidobacteria. Can J Microbiol. 2006;52(10):924-933.

51. Arslanoglu S, Moro GE, Boehm G. Early supplementation of prebiotic oligosaccharides protects formula-fed infants against infections during the first 6 months of life. J Nutr. 2007;137(11):2420-2424. 
52. Shadid R, Haarman M, Knol J, et al. Effects of galactooligosaccharide and long-chain fructooligosaccharide supplementation during pregnancy on maternal and neonatal microbiota and immunity - a randomized, double-blind, placebo-controlled study. Am J Clin Nutr. 2007; 86(5):1426-1437.

53. Steed H, Macfarlane GT, Macfarlane S. Prebiotics, synbiotics and inflammatory bowel disease. Mol Nutr Food Res. 2008;52(8):898-905.

54. Shimizu K, Ogura H, Asahara T, et al. Probiotic/synbiotic therapy for treating critically ill patients from a gut microbiota perspective. Dig Dis Sci. 2013;58(1):23-32.

55. Blümer N, Sel S, Virna S, et al. Perinatal maternal application of Lactobacillus rhamnosus GG suppresses allergic airway inflammation in mouse offspring. Clin Exp Allergy. 2007;37(3):348-357.

56. Feleszko W, Jaworska J, Rha RD, et al. Probiotic-induced suppression of allergic sensitization and airway inflammation is associated with an increase of T regulatory-dependent mechanisms in a murine model of asthma. Clin Exp Allergy. 2007;37(4):498-505.

57. Rigaux P, Daniel C, Hisbergues M, et al. Immunomodulatory properties of Lactobacillus plantarum and its use as a recombinant vaccine against mite allergy. Allergy. 2009;64(3):406-414.

58. Repa A, Grangette C, Daniel C, et al. Mucosal co-application of lactic acid bacteria and allergen induces counter-regulatory immune responses in a murine model of birch pollen allergy. Vaccine. 2003; 22(1):87-95.

59. Forsythe P, Inman MD, Bienenstock J. Oral treatment with live Lactobacillus reuteri inhibits the allergic airway response in mice. Am J Respir Crit Care Med. 2007;175(6):561-569.

60. Karimi K, Inman MD, Bienenstock J, Forsythe P. Lactobacillus reuteriinduced regulatory $\mathrm{T}$ cells protect against an allergic airway response in mice. Am J Respir Crit Care Med. 2009;179(3):186-193.

61. Stockert K, Schneider B, Porenta G, Rath R, Nissel H, Eichler I. Laser acupuncture and probiotics in school age children with asthma: a randomized, placebo-controlled pilot study of therapy guided by principles of traditional Chinese medicine. Pediatr Allergy Immunol. 2007;18(2):160-166.

62. Moreira A, Kekkonen R, Korpela R, Delgado L, Haahtela T. Allergy in marathon runners and effect of Lactobacillus GG supplementation on allergic inflammatory markers. Respir Med. 2007;101(6):1123-1131.

63. Helin T, Haahtela S, Haahtela T. No effect of oral treatment with an intestinal bacterial strain, Lactobacillus rhamnosus (ATCC 53103), on birch-pollen allergy: a placebo-controlled double-blind study. Allergy. 2002;57(3):243-246.

64. Vliagoftis H, Kouranos VD, Betsi GI, Falagas ME. Probiotics for the treatment of allergic rhinitis and asthma: systematic review of randomized controlled trials. Ann Allergy Asthma Immunol. 2008;101(6):570-579.

65. Viljanen M, Savilahti E, Haahtela T, et al. Probiotics in the treatment of atopic eczema/dermatitis syndrome in infants: a double-blind placebocontrolled trial. Allergy. 2005;60(4):494-500.

66. Wickens K, Black PN, Stanley TV, et al. A differential effect of 2 probiotics in the prevention of eczema and atopy: a double-blind, randomized, placebo-controlled trial. J Allergy Clin Immunol. 2008; 122(4):788-794.

67. Rosenfeldt V, Benfeldt E, Nielsen SD, et al. Effect of probiotic Lactobacillus strains in children with atopic dermatitis. J Allergy Clin Immunol. 2003;111(2):389-395.

68. Betsi GI, Papadavid E, Falagas ME. Probiotics for the treatment or prevention of atopic dermatitis: a review of the evidence from randomized controlled trials. Am J Clin Dermatol. 2008;9(2):93-103.

69. Doege K, Grajecki D, Zyriax BC, Detinkina E, Eulenburg C, Buhling KJ. Impact of maternal supplementation with probiotics during pregnancy on atopic eczema in childhood - a meta-analysis. Br J Nutr. 2012; 107(1):1-6.

70. Pelucchi C, Chatenoud L, Turati F, et al. Probiotics supplementation during pregnancy or infancy for the prevention of atopic dermatitis: a metaanalysis. Epidemiology. 2012;23(3):402-414.

71. Han Y, Kim B, Ban J, et al. A randomized trial of Lactobacillus plantarum CJLP133 for the treatment of atopic dermatitis. Pediatr Allergy Immunol. 2012;23(7):667-673.
72. Kalliomaki M, Salminen S, Poussa T, Arvilommi H, Isolauri E. Probiotics and prevention of atopic disease: 4-year follow-up of a randomised placebo-controlled trial. Lancet. 2003;361(9372):1869-1871.

73. Kopp MV, Salfeld P. Probiotics and prevention of allergic disease. Curr Opin Clin Nutr Metab Care. 2009;12(3):298-303.

74. Taylor AL, Dunstan JA, Prescott SL. Probiotic supplementation for the first 6 months of life fails to reduce the risk of atopic dermatitis and increases the risk of allergen sensitization in high-risk children: a randomized controlled trial. J Allergy Clin Immunol. 2007;119(1):184-191.

75. Gore C, Custovic A, Tannock GW, et al. Treatment and secondary prevention effects of the probiotics Lactobacillus paracasei or Bifidobacterium lactis on early infant eczema: randomized controlled trial with follow-up until age 3 years. Clin Exp Allergy. 2012;42(1):112-122.

76. Prescott SL, Björkstén B. Probiotics for the prevention or treatment of allergic diseases. J Allergy Clin Immunol. 2007;120(2):255-262.

77. Osborn DA, Sinn JK. Probiotics in infants for prevention of allergic disease and food hypersensitivity. Cochrane Database Syst Rev. 2007; (4):CD006475.

78. Boyle RJ, Bath-Hextall FJ, Leonardi-Bee J, Murrell DF, Tang ML. Probiotics for the treatment of eczema: a systematic review. Clin Exp Allergy. 2009;39(8):1117-1127.

79. Boyle RJ, Bath-Hextall FJ, Leonardi-Bee J, Murrell DF, Tang ML. Probiotics for treating eczema. Cochrane Database Syst Rev. 2008;(4): CD006135.

80. Lee J, Seto D, Bielory L. Meta-analysis of clinical trials of probiotics for prevention and treatment of pediatric atopic dermatitis. $J$ Allergy Clin Immunol. 2008;121(1):116-121.e11.

81. Kalliomäki M, Salminen S, Poussa T, Isolauri E. Probiotics during the first 7 years of life: a cumulative risk reduction of eczema in a randomized, placebo-controlled trial. J Allergy Clin Immunol. 2007; 119(4):1019-1121.

82. Kopp MV, Hennemuth I, Heinzmann A, Urbanek R. Randomized, double-blind, placebo-controlled trial of probiotics for primary prevention: no clinical effects of Lactobacillus GG supplementation. Pediatrics. 2008;121(4):e850-e856.

83. Dotterud CK, Storrø O, Johnsen R, Øien T. Probiotics in pregnant women to prevent allergic disease: a randomized, double-blind trial. Br J Dermatol. 2010;163(3):616-623.

84. Penders J, Stobberingh EE, van den Brandt PA, Thijs C. The role of the intestinal microbiota in the development of atopic disorders. Allergy. 2007;62(11):1223-1236.

85. Peng GC, Hsu CH. The efficacy and safety of heat-killed Lactobacillus paracasei for treatment of perennial allergic rhinitis induced by housedust mite. Pediatr Allergy Immunol. 2005;16(5):433-438.

86. Ivory K, Chambers SJ, Pin C, Prieto E, Arqués JL, Nicoletti C. Oral delivery of Lactobacillus casei Shirota modifies allergen-induced immune responses in allergic rhinitis. Clin Exp Allergy. 2008;38(8):1282-1289.

87. Felice G, Barletta B, Butteroni C, et al. Use of probiotic bacteria for prevention and therapy of allergic diseases: studies in mouse model of allergic sensitization. J Clin Gastroenterol. 2008;42 Suppl 3 Pt 1:S130-S132.

88. Giovannini M, Agostoni C, Riva E, et al. A randomized prospective double blind controlled trial on effects of long-term consumption of fermented milk containing Lactobacillus casei in pre-school children with allergic asthma and/or rhinitis. Pediatr Res. 2007;62(2):215-220.

89. Kuitunen M, Kukkonen K, Juntunen-Backman K, et al. Probiotics prevent IgE-associated allergy until age 5 years in cesarean-delivered children but not in the total cohort. J Allergy Clin Immunol. 2009;123(2):335-341.

90. Wickens K, Black P, Stanley TV, et al. A protective effect of Lactobacillus rhamnosus HN001 against eczema in the first 2 years of life persists to age 4 years. Clin Exp Allergy. 2012;42(7):1071-1079.

91. Kawase M, He F, Kubota A, et al. Effect of fermented milk prepared with two probiotic strains on Japanese cedar pollinosis in a double-blind placebo-controlled clinical study. Int J Food Microbiol. 2009;128(3):429-434.

92. Morita H, He F, Kawase M, et al. Preliminary human study for possible alteration of serum immunoglobulin E production in perennial allergic rhinitis with fermented milk prepared with Lactobacillus gasseri TMC0356. Microbiol Immunol. 2006;50(9):701-706. 
93. Xiao JZ, Kondo S, Yanagisawa N, et al. Effect of probiotic Bifidobacterium longum BB536 [corrected] in relieving clinical symptoms and modulating plasma cytokine levels of Japanese cedar pollinosis during the pollen season: a randomized double-blind, placebo-controlled trial. J Investig Allergol Clin Immunol. 2006;16(2): $86-93$.

94. Xiao JZ, Kondo S, Yanagisawa N, et al. Probiotics in the treatment of Japanese cedar pollinosis: a double-blind placebo-controlled trial. Clin Exp Allergy. 2006;36(11):1425-1435.

95. Tamura M, Shikina T, Morihana T, et al. Effects of probiotics on allergic rhinitis induced by Japanese cedar pollen: randomized doubleblind, placebo-controlled clinical trial. Int Arch Allergy Immunol. 2007;143(1):75-82.

96. Isolauri E, Rautava S, Kalliomäki M, Kirjavainen P, Salminen S. Role of probiotics in food hypersensitivity. Curr Opin Allergy Clin Immunol. 2002;2(3):263-271.

97. Barletta B, Rossi G, Schiavi E, et al. Probiotic VSL\#3-induced TGF- $\beta$ ameliorates food allergy inflammation in a mouse model of peanut sensitization through the induction of regulatory $\mathrm{T}$ cells in the gut mucosa. Mol Nutr Food Res. 2013;57(12):2233-2244.

98. Shida K, Takahashi R, Iwadate E, et al. Lactobacillus casei strain Shirota suppresses serum immunoglobulin E and immunoglobulin G1 responses and systemic anaphylaxis in a food allergy model. Clin Exp Allergy. 2002;32(4):563-570.

99. Isolauri E, Arvola T, Sütas Y, Moilanen E, Salminen S. Probiotics in the management of atopic eczema. Clin Exp Allergy. 2000;30(11): $1604-1610$

100. Hol J, van Leer EH, Elink Schuurman BE, et al. The acquisition of tolerance toward cow's milk through probiotic supplementation: a randomized, controlled trial. J Allergy Clin Immunol. 2008;121(6): $1448-1454$.

101. Soh SE, Aw M, Gerez I, et al. Probiotic supplementation in the first 6 months of life in at risk Asian infants - effects on eczema and atopic sensitization at the age of 1 year. Clin Exp Allergy. 2009;39(4): 571-578.

102. Shanahan F. A commentary on the safety of probiotics. Gastroenterol Clin North Am. 2012;41(4):869-876.

103. Fedorak RN, Madsen KL. Probiotics and prebiotics in gastrointestinal disorders. Curr Opin Gastroenterol. 2004;20(2):146-155.

104. Borriello SP, Hammes WP, Holzapfel W, et al. Safety of probiotics that contain lactobacilli or bifidobacteria. Clin Infect Dis. 2003; 36(6):775-780.

105. Mackay AD, Taylor MB, Kibbler CC, Hamilton-Miller JM. Lactobacillus endocarditis caused by a probiotic organism. Clin Microbiol Infect. 1999;5(5):290-292.

106. Rautio M, Jousimies-Somer H, Kauma H, et al. Liver abscess due to a Lactobacillus rhamnosus strain indistinguishable from L. rhamnosus strain GG. Clin Infect Dis. 1999;28(5):1159-1160.

107. Allen SJ, Jordan S, Storey M, et al. Dietary supplementation with lactobacilli and bifidobacteria is well tolerated and not associated with adverse events during late pregnancy and early infancy. $J$ Nutr. 2010;140(3):483-488.

108. Martin-Muñoz MF, Fortuni M, Caminoa M, Belver T, Quirce S, Caballero T. Anaphylactic reaction to probiotics: cow's milk and hen's egg allergens in probiotic compounds. Pediatr Allergy Immunol. 2012;23(8):778-784.

109. Robin F, Paillard C, Marchandin H, Demeocq F, Bonnet R, Hennequin C. Lactobacillus rhamnosus meningitis following recurrent episodes of bacteremia in a child undergoing allogeneic hematopoietic stem cell transplantation. J Clin Microbiol. 2010;48(11): $4317-4319$.

110. Vahabnezhad E, Mochon AB, Wozniak LJ, Ziring DA. Lactobacillus bacteremia associated with probiotic use in a pediatric patient with ulcerative colitis. J Clin Gastroenterol. 2013;47(5):437-439.

111. Luong ML, Sareyyupoglu B, Nguyen MH, et al. Lactobacillus probiotic use in cardiothoracic transplant recipients: a link to invasive Lactobacillus infection? Transpl Infect Dis. 2010;12(6): 561-564.
112. Cabana MD, Shane AL, Chao C, Oliva-Hemker M. Probiotics in primary care pediatrics. Clin Pediatr (Phila). 2006;45(5):405-410.

113. Dai M, Lu J, Wang Y, Liu Z, Yuan Z. In vitro development and transfer of resistance to chlortetracycline in Bacillus subtilis. J Microbiol. 2012;50(5):807-812.

114. Arslanoglu S, Moro GE, Schmitt J, Tandoi L, Rizzardi S, Boehm G. Early dietary intervention with a mixture of prebiotic oligosaccharides reduces the incidence of allergic manifestations and infections during the first two years of life. J Nutr. 2008;138(6):1091-1095.

115. Arslanoglu S, Moro GE, Boehm G, Wienz F, Stahl B, Bertino E. Early neutral prebiotic oligosaccharide supplementation reduces the incidence of some allergic manifestations in the first 5 years of life. J Biol Regul Homeost Agents. 2012;26(3 Suppl):49-59.

116. Osborn DA, Sinn JK. Prebiotics in infants for prevention of allergy. Cochrane Database Syst Rev. 2013;3:CD006474.

117. Wu KG, Li TH, Peng HJ. Lactobacillus salivarius plus fructooligosaccharide is superior to fructo-oligosaccharide alone for treating children with moderate to severe atopic dermatitis: a double-blind, randomized, clinical trial of efficacy and safety. Br J Dermatol. 2012; 166(1):129-136.

118. van der Aa LB, van Aalderen WM, Heymans HS, et al. Synbiotics prevent asthma-like symptoms in infants with atopic dermatitis. Allergy. 2011;66(2):170-177.

119. Kukkonen K, Savilahti E, Haahtela T, et al. Long-term safety and impact on infection rates of postnatal probiotic and prebiotic (synbiotic) treatment: randomized, double-blind, placebo-controlled trial. Pediatrics. 2008;122(1):8-12.

120. Osborn DA, Sinn J. Soy formula for prevention of allergy and food intolerance in infants. Cochrane Database Syst Rev. 2004;(3): CD003741.

121. Osborn DA, Sinn J. Formulas containing hydrolysed protein for prevention of allergy and food intolerance in infants. Cochrane Database Syst Rev. 2003;(4):CD003664.

122. Lowe AJ, Dharmage SC, Allen KJ, Tang ML, Hill DJ. The role of partially hydrolyzed whey formula for the prevention of allergic disease: evidence and gaps. Expert Rev Clin Immunol. 2013;9(1):31-41.

123. Alexander DD, Cabana MD. Partially hydrolyzed $100 \%$ whey protein infant formula and reduced risk of atopic dermatitis: a meta-analysis. J Pediatr Gastroenterol Nutr. 2010;50(4):422-430.

124. Szajewska H, Horvath A. Meta-analysis of the evidence for a partially hydrolyzed $100 \%$ whey formula for the prevention of allergic diseases. Curr Med Res Opin. 2010;26(2):423-437.

125. Su J, Prescott S, Sinn J, et al. Cost-effectiveness of partially-hydrolyzed formula for prevention of atopic dermatitis in Australia. J Med Econ. 2012;15(6):1064-1077.

126. Foliaki S, Pearce N, Björkstén B, Mallol J, Montefort S, von Mutius E. Antibiotic use in infancy and symptoms of asthma, rhinoconjunctivitis, and eczema in children 6 and 7 years old: International Study of Asthma and Allergies in Childhood Phase III. J Allergy Clin Immunol. 2009;124(5):982-989.

127. Batlles-Garrido J, Torres-Borrego J, Rubí-Ruiz T, et al. Prevalence and factors linked to allergic rhinitis in 10 and 11-year-old children in Almeria. ISAAC Phase II, Spain. Allergol Immunopathol (Madr). 2010; 38(3):135-141.

128. Magnusson J, Kull I, Rosenlund H, et al. Fish consumption in infancy and development of allergic disease up to age 12 y. Am JClin Nutr. 2013; 97(6):1324-1330.

129. Seo JH, Kwon SO, Lee SY, et al. Association of antioxidants with allergic rhinitis in children from Seoul. Allergy Asthma Immunol Res. 2013;5(2):81-87.

130. Moyes CD, Clayton T, Pearce N, et al. Time trends and risk factors for rhinoconjunctivitis in New Zealand children: an International Study of Asthma and Allergies in Childhood (ISAAC) survey. $J$ Paediatr Child Health. 2012;48(10):913-920.

131. Penaranda A, Aristizabal G, Garcia E, Vásquez C, RodríguezMartinez CE. Rhinoconjunctivitis prevalence and associated factors in school children aged 6-7 and 13-14 years old in Bogota, Colombia. Int J Pediatr Otorhinolaryngol. 2012;76(4):530-535. 
132. Beasley R, Clayton T, Crane J, et al. Association between paracetamol use in infancy and childhood, and risk of asthma, rhinoconjunctivitis, and eczema in children aged 6-7 years: analysis from Phase Three of the ISAAC programme. Lancet. 2008;372(9643):1039-1048.

133. Chatzi L, Kogevinas M. Prenatal and childhood Mediterranean diet and the development of asthma and allergies in children. Public Health Nutr. 2009;12(9A):1629-1634.

134. Meyerhardt JA, Niedzwiecki D, Hollis D, et al. Association of dietary patterns with cancer recurrence and survival in patients with stage III colon cancer. JAMA. 2007;298(7):754-764.

135. Psaltopoulou T, Naska A, Orfanos P, Trichopoulos D, Mountokalakis T, Trichopoulou A. Olive oil, the Mediterranean diet, and arterial blood pressure: the Greek European Prospective Investigation into Cancer and Nutrition (EPIC) study. Am J Clin Nutr. 2004; 80(4):1012-1018.

136. Arvaniti F, Priftis KN, Papadimitriou A, et al. Salty-snack eating, television or video-game viewing, and asthma symptoms among 10- to 12-year-old children: the PANACEA study. J Am Diet Assoc. 2011; 111(2):251-257.

137. de Batlle J, Garcia-Aymerich J, Barraza-Villarreal A, Antó JM, Romieu I. Mediterranean diet is associated with reduced asthma and rhinitis in Mexican children. Allergy. 2008;63(10):1310-1316.

138. Chatzi L, Apostolaki G, Bibakis I, et al. Protective effect of fruits, vegetables and the Mediterranean diet on asthma and allergies among children in Crete. Thorax. 2007;62(8):677-683.

139. Barros R, Moreira A, Fonseca J, et al. Adherence to the Mediterranean diet and fresh fruit intake are associated with improved asthma control. Allergy. 2008;63(7):917-923.

140. Garcia-Marcos L, Castro-Rodriguez JA, Weinmayr G, Panagiotakos DB, Priftis KN, Nagel G. Influence of Mediterranean diet on asthma in children: a systematic review and meta-analysis. Pediatr Allergy Immunol. 2013;24(4):330-338.

141. Tamay Z, Akcay A, Ergin A, Güler N. Dietary habits and prevalence of allergic rhinitis in 6 to 7-year-old schoolchildren in Turkey. Allergol Int. 2014;63(4):553-562.

142. Wegener G. 'Let food be thy medicine, and medicine be thy food': Hippocrates revisited. Acta Neuropsychiatr. 2014;26(1):1-3.

143. Jerschow E, McGinn AP, de Vos G, et al. Dichlorophenol-containing pesticides and allergies: results from the US National Health and Nutrition Examination Survey 2005-2006. Ann Allergy Asthma Immunol. 2012;109(6):420-425.
144. American College of Allergy, Asthma and Immunology. Types of food allergy: oral allergy syndrome. 2014. Available from: http://acaai. org/allergies/types/food-allergies/types-food-allergy/oral-allergysyndrome. Accessed July 2, 2015.

145. Bener A, Ehlayel MS, Bener ZH, Hamid Q. The impact of vitamin D deficiency on asthma, allergic rhinitis and wheezing in children: an emerging public health problem. J Family Community Med. 2014;21(3): 154-161.

146. Bener A, Ehlayel MS, Tulic MK, Hamid Q. Vitamin D deficiency as a strong predictor of asthma in children. Int Arch Allergy Immunol. 2012; 157(2):168-175.

147. Rovner AJ, O’Brien KO. Hypovitaminosis D among healthy children in the United States: a review of the current evidence. Arch Pediatr Adolesc Med. 2008;162(6):513-519.

148. Litonjua AA. Childhood asthma may be a consequence of vitamin D deficiency. Curr Opin Allergy Clin Immunol. 2009;9(3):202-207.

149. Bath-Hextall FJ, Jenkinson C, Humphreys R, Williams HC. Dietary supplements for established atopic eczema. Cochrane Database Syst Rev. 2012;2:CD005205.

150. Denburg JA, Hatfield HM, Cyr MM, et al. Fish oil. Pediatr Res. 2005;57(2):276-281.

151. Wijga AH, van Houwelingen AC, Kerkhof M, et al. Breast milk fatty acids and allergic disease in preschool children: the Prevention and Incidence of Asthma and Mite Allergy birth cohort study. J Allergy Clin Immunol. 2006;117(2):440-447.

152. Oddy WH, Pal S, Kusel MM, et al. Atopy, eczema and breast milk fatty acids in a high-risk cohort of children followed from birth to 5 yr. Pediatr Allergy Immunol. 2006;17(1):4-10.

153. Peat JK, Mihrshahi S, Kemp AS, et al. Three-year outcomes of dietary fatty acid modification and house dust mite reduction in the Childhood Asthma Prevention Study. J Allergy Clin Immunol. 2004; 114(4):807-813.

154. Mihrshahi S, Peat JK, Webb K, Oddy W, Marks GB, Mellis CM. Effect of omega-3 fatty acid concentrations in plasma on symptoms of asthma at 18 months of age. Pediatr Allergy Immunol. 2004; 15(6):517-522.
Therapeutics and Clinical Risk Management

\section{Publish your work in this journal}

Therapeutics and Clinical Risk Management is an international, peerreviewed journal of clinical therapeutics and risk management, focusing on concise rapid reporting of clinical studies in all therapeutic areas, outcomes, safety, and programs for the effective, safe, and sustained use of medicines. This journal is indexed on PubMed Central, CAS,

\section{Dovepress}

EMBase, Scopus and the Elsevier Bibliographic databases. The manuscript management system is completely online and includes a very quick and fair peer-review system, which is all easy to use. Visit http://www.dovepress.com/testimonials.php to read real quotes from published authors. 